\title{
Laboreal
}

Volume $5 \mathrm{~N}^{\circ} 2$ | 2009

Varia

\section{Entre a concepção e a execução : a percepção dos conflitos no cotidiano do arquiteto}

Entre la concepción y la ejecución : la percepción de los conflictos en el cuotidiano del arquitecto

Entre la conception et la mise en oeuvre : la perception des conflits dans le quotidien des architectes

Among the conception and the execution: the perception of conflict in daily architect

Fernanda Flávia Cockell, Daniel Perticarrari e Alessandra Mara Cockell

\section{(2) OpenEdition}

Journals

Edição electrónica

URL: http://journals.openedition.org/laboreal/9756

DOI: $10.4000 /$ laboreal.9756

ISSN: 1646-5237

Editora

Universidade do Porto

Refêrencia eletrónica

Fernanda Flávia Cockell, Daniel Perticarrari e Alessandra Mara Cockell, « Entre a concepção e a execução : a percepção dos conflitos no cotidiano do arquiteto ", Laboreal [Online], Volume 5 No2 2009, posto online no dia 01 dezembro 2009, consultado o 10 outubro 2019. URL : http:// journals.openedition.org/laboreal/9756; DOI : 10.4000/laboreal.9756

Este documento foi criado de forma automática no dia 10 outubro 2019.

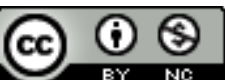

Laboreal está licenciado com uma Licença Creative Commons - Atribuição-NãoComercial 4.0 Internacional. 


\section{Entre a concepção e a execução : a percepção dos conflitos no cotidiano do arquiteto}

Entre la concepción y la ejecución : la percepción de los conflictos en el cuotidiano del arquitecto

Entre la conception et la mise en oeuvre : la perception des conflits dans le quotidien des architectes

Among the conception and the execution: the perception of conflict in daily architect

Fernanda Flávia Cockell, Daniel Perticarrari e Alessandra Mara Cockell

\section{NOTA DO EDITOR}

Manuscrito recebido em : Maio/2008

Aceite após peritagem em : Setembro /2009

\section{Introdução}

1 A partir dos anos 90, a construção de edificações apresenta profundas modificações motivadas pelo processo de abertura econômica e reestruturação produtiva. Novas tecnologias passaram a ser empregadas, impulsionadas pela evolução dos materiais de construção, demandando a entrada de novos equipamentos e novas técnicas de execução. Surgem empresas especializadas no fornecimento de serviços e insumos de alta tecnologia e na execução de obras de alto padrão de acabamento final (Farah, 1996). Simultaneamente a este processo, ocorre a expansão dos recursos dos sistemas computacionais desenvolvidos para os trabalhos gráficos em projetos - Computer Aided Design (CAD), empregados pelos departamentos de arquitetura para acompanhar a 
modernização dos projetos, para atender a rapidez e integração de execução das obras e para satisfazer a demanda dos clientes.

2 Tais exigências tecnológicas e de qualidade passam a demandar do arquiteto novas competências e maiores necessidades de qualificação para valer-se de novas ferramentas computadorizadas de desenho e de execução de projetos (Bassalo, 1995). Da prancheta ao computador, em poucos anos, estes profissionais vivenciam a revolução do modo de execução, armazenagem, organização e re-projeto de desenhos, tendo sua atividade de trabalho completamente transformada (Speck, 2005).

3 Houve a intensificação da jornada e do ritmo de trabalho destes profissionais, surgindo, portanto, novos condicionantes técnicos, ambientais, organizacionais e relacionais capazes de gerar sofrimentos físicos e psíquicos. Diante deste contexto, este artigo tem como objetivo mostrar, a partir de um estudo de caso, como os condicionantes da atividade de trabalho de um grupo de arquitetas, de uma empresa de construção civil brasileira, vêm se apresentando nocivos à saúde destas trabalhadoras.

\section{Estratégias de investigação}

4 Para apreendermos a percepção das arquitetas sobre o trabalho realizado e sobre os conflitos vivenciados, optamos como forma de abordagem o método qualitativo. Esta opção metodológica deve-se à natureza do problema a ser estudado, da complexidade do objeto de estudo e do recorte da pesquisa.

5 Conjuntamente, diante da demanda formulada, empregamos a Análise Ergonômica do Trabalho (AET) para avaliarmos a tarefa, a atividade real, as condições de trabalho, os condicionantes da atividade, as diversidades entre o prescrito e o real e para construirmos conjuntamente com os diferentes atores envolvidos um conjunto de proposições e soluções para os problemas encontrados. Trata-se, segundo Wisner (2004), de um modelo metodológico de intervenção e de transformação capaz de apreender a complexidade existente na relação do homem com o trabalho, sem colocar em prova um modelo escolhido a priori. A aplicação desta metodologia pressupõe a participação do trabalhador no processo de intervenção ergonômica, bem como prioriza o estudo da situação real de trabalho.

6 No estudo do caso analisado foram feitos, primeiramente, contatos com o grupo de arquitetas da empresa para o entendimento do problema e para discutir estratégias que possibilitassem tornar o estudo da atividade viável. Vale ressaltar que a demanda não partiu da empresa.

7 A negociação com a diretoria da empresa para a entrada dos pesquisadores durou cerca de 15 dias. A única restrição feita foi que o ritmo de trabalho não fosse alterado. Desde o início, a empresa deixou claro que o estudo poderia ser realizado, mas somente permitiria modificações do layout, caso fossem economicamente viáveis, não sendo objetivo da empresa alterar a organização do trabalho.

8 Mesmo sem o comprometimento e interesse da instituição pela transformação do trabalho, as arquitetas solicitaram o estudo, acreditando ser esse o único meio de tornar visível os sofrimentos vivenciados por elas. Após esse período de negociação, os pesquisadores conseguiram ter acesso ao local de trabalho. Todas as informações sobre a empresa, sobre o departamento e dados de saúde tiveram que ser coletadas através de entrevistas com as arquitetas que trabalham e que já trabalharam no setor. A única 
documentação fornecida pela empresa refere-se ao trabalho prescrito, aos cronogramas das obras e as competências esperadas do arquiteto pela empresa.

Inicialmente, foram feitas Observações Abertas de Campo. Este contato inicial com a atividade do arquiteto permitiu a compreensão relativamente superficial do processo técnico e das tarefas por ele realizadas, assim como do funcionamento geral da empresa. Durante esta primeira aproximação, foi possível apenas coletar comentários dos trabalhadores sobre suas condições de trabalho, estado de saúde e relação com os demais setores. Além disso, esta etapa permitiu também maior contato entre pesquisador e trabalhadores, estabelecendo relações de confiança, fundamentais para o sucesso da análise a ser realizada. Após esse período de familiarização com o campo e com os trabalhadores, foram realizadas observações sistemáticas da atividade de trabalho, da organização do trabalho e dos modos operatórios adotados. As verbalizações espontâneas ocorridas no decorrer da atividade foram registradas em áudio, permitindo acompanhar as reações das arquitetas diante de cada situação enfrentada e, posteriormente, autoconfrontá-las. Durante as observações, também foram formuladas questões contextualizadas relacionadas com os fatos ocorridos (Wisner, 1994). Além das cinco arquitetas que trabalham no setor, pudemos entrevistar duas arquitetas que tinham pedido demissão devido às altas cargas de trabalho, dois engenheiros e uma estagiária do setor. Os dados coletados nas entrevistas foram transcritos e, posteriormente, analisados. Em média, as entrevistas com as arquitetas tinham, no total, duas horas e meia de duração. Analisamos também as condições físicas dos postos de trabalho, níveis de ruído e de iluminação, para que a análise do ambiente físico, previamente solicitada, fosse realizada.

É importante mencionarmos que, no decorrer do estudo, à medida que o real era compreendido, foi preciso repensar as nossas modalidades de investigação para que pudéssemos entender o sofrimento vivenciado pelo grupo de arquitetas. Conforme afirma Dejours (2008a, p. 37), "quanto mais se busca apreender a especificidade do esforço envolvido, mais é necessário penetrar na vivência do indivíduo que trabalha”. A esse respeito, Dejours (2008b, p. 117) nos ensina que, para analisarmos o sofrimento pelo trabalho, precisamos ir além do que apenas entender a realidade dos fatos do trabalho, sendo preciso apreender a subjetividade dos trabalhadores a partir da "dimensão do comentário". Desta forma, a partir da experiência subjetiva de cada uma das arquitetas sobre o seu trabalho, pudemos investigar em que medida a distância entre o prescrito e o real, os aspectos organizacionais, as dificuldades relacionais e de comunicação, bem como as novas tecnologias utilizadas, tornam o trabalho das arquitetas mais penoso, sobretudo do ponto de vista psíquico, com efeitos visíveis para a saúde física e mental do grupo pesquisado.

\section{A demanda das arquitetas}

11 A demanda inicial pelo estudo foi formulada diretamente pelas trabalhadoras. Essa demanda social, procurava inicialmente soluções de mobiliário para os problemas músculo-esqueléticos. Contudo, com o decorrer do estudo, a demanda foi sendo modificada; pois era preciso encontrar respostas para os motivos do adoecimento e sofrimento vivenciado pelas arquitetas e para a alta rotatividade nos últimos sete anos.

De acordo com Guérin, Laville, Daniellou, Duraffourg e Kerguelen (2001), a construção da ação ergonômica inicia-se com a etapa da análise da demanda. Nesta fase, são 
definidos os problemas a serem analisados, as condições de realização do estudo, os resultados que poderão ser esperados, os meios necessários, os prazos de execução e os possíveis desafios a serem enfrentados. A demanda pode ser construída na origem de um projeto de concepção, durante as disfunções de um sistema já implantado ou como parte de um quadro de evolução permanente, onde novos condicionantes são introduzidos a cada mudança tecnológica ou organizacional. Infelizmente, as demandas formuladas com o objetivo de resolver disfunções do sistema já implantado são mais freqüentes entre as empresas brasileiras do que aquelas concebidas antes da implantação de um novo sistema de produção.

13 A formulação nem sempre é explícita, de forma que em tais casos, cabe ao pesquisador a responsabilidade primeira de reformulá-la, identificando - através do confronto dos diferentes pontos de vista - o objeto e as possibilidades da ação. Aquelas demandas formuladas de maneira mais clara também exigem a negociação por parte do pesquisador antes da apresentação final da proposta de ação ; para a caracterização das questões apresentadas e para a identificação dos outros problemas potenciais - ainda não relatados - da situação de trabalho (Santos \& Fialho, 1995).

14 A demanda pode partir da empresa, dos trabalhadores, sindicatos e instituições públicas legais. De acordo com a sua origem, o resultado da ação poderá não ser conclusivo, pois as dificuldades de negociação entre os diferentes pontos de vista, muitas vezes contraditórios, e a impossibilidade de atuação impedem a transformação efetiva do contexto.

15 As demandas formuladas pela direção da empresa são, no Brasil, as mais freqüentemente requisitadas. Tal origem de demanda está relacionada, normalmente, a transformaçães consideráveis na situação de trabalho, à implantação de um novo sistema de produção, a redução dos índices de absenteísmo por patologias relacionadas ao trabalho ou cumprimento das normas estabelecidas pela legislação vigente (Guérin, Laville, Daniellou, Duraffourg \& Kerguelen, 2001). Este tipo de demanda possui algumas vantagens, como por exemplo, maior comprometimento da instituição durante as fases da AET, acesso aos documentos sobre indicadores relativos à eficácia e à saúde, financiamento para as fases de projetação e simulação, maiores possibilidades de atuação na organização do trabalho e engajamento de todas as racionalidades durante as etapas do estudo. No entanto, como afirmam Campello, Oliveira, Netz e Machado (2002), este tipo de origem empresarial pode ficar restrito aos pontos de interesse específicos do empregador, tanto na fase de investigação quanto na de implementação das medidas propostas, ao desconsiderar o diagnóstico construído.

Enquanto as demandas formuladas diretamente pelos trabalhadores, como no caso estudado, são normalmente pontuais, relacionadas com problemas específicos do posto de trabalho e, muitas vezes, não são prioridade na política e gestão da empresa. Santos e Fialho (1995) acrescentam ainda que a demanda formulada pelos trabalhadores se manifesta ao longo da realização de toda intervenção ergonômica, independente dos motivos iniciais que levaram à realização do estudo. Não há duvida de que tal origem de demanda carrega algumas desvantagens, como dificuldade de acesso aos dados da empresa e de saúde, de confrontação entre os departamentos e posições hierárquicas, de envolvimento de todos os atores sociais e, principalmente, da transformação do trabalho e da construção de contratos sociais entre os diferentes atores envolvidos. A demanda, estabelecida pelos trabalhadores, cresce com o aumento do nível de instrução geral e profissional da população de trabalhadores e com a facilidade de acesso a 
informações pela Internet, pois uma parcela maior da população economicamente ativa, ainda insignificante para a realidade brasileira, passou a exigir, nas últimas décadas, condições melhores de conforto e de segurança e respostas para a gênese do sofrimento por eles vivenciados (Wisner, 1994).

\section{O Trabalho do arquiteto}

17 O estudo foi realizado em uma empresa de construção civil que atua no mercado brasileiro há mais de 50 anos. Trata-se de uma construtora de capital nacional que atua no ramo de edificações, na prestação de serviços a terceiros sob forma de empreitada ou administração e na incorporação de obras residenciais e comerciais de sua propriedade, com elevado padrão de acabamento.

O departamento de arquitetura da empresa é formado por cinco arquitetas. Mulheres, entre 27 e 34 anos, sendo três casadas e duas solteiras.

As arquitetas possuem uma gerência imediatamente superior que, por sua vez, está diretamente ligada ao presidente da empresa.

O espaço físico da sala possui 38,5 metros quadrados e cada arquiteta trabalha em um posto de trabalho individual e fixo. Existem cinco mesas para computador e uma do tipo prancheta. As demais áreas e equipamentos do setor são de uso comum.

21 As arquitetas são registradas em carteira de trabalho, possuem alguns benefícios como plano de saúde e vale refeição. O salário recebido é maior do que a média local para a mesma função, média de 10 salários mínimos mensais. Trabalham de segunda a sextafeira, no mínimo oito horas por dia, com intervalo de duas horas de almoço, sendo que chegam quase que rotineiramente a trabalhar mais de dez horas por dia. Quase todo o trabalho é realizado com o uso de programas computadorizados, passando grande parte do seu tempo sentadas em frente ao terminal de vídeo. A utilização do computador ocorre conjuntamente com o manuseio de documentos, projetos e catálogos. As mesas disponibilizadas limitam-se ao espaço para teclado e mouse, obrigando o usuário a utilizar a mínima área restante para apoio do material manuseado.

Como não existe uma estação de trabalho que atenda todas as necessidades de manuseio dos materiais, esses ficam fora da zona de alcance normal das mãos, causando movimentos extremos de tronco e de ombro. Há queixas das trabalhadoras quanto a isso :

A gente trabalha muito com folhas de papel grandes e difíceis de manusear. Aí o jeito que eu encontro é puxar uma cadeira aqui para o lado e colocar a folha. Mas mesmo assim é ruim porque fico virada para o lado e meu corpo dói todo (Arquiteta).

\subsection{A tarefa prescrita}

Mediante o material que tivemos acesso, foi possível analisarmos o ambiente técnico, econômico e social da empresa. Constatamos que, uma obra será lucrativa quanto maior for a quantidade de informações prévias e quanto menores forem os imprevistos. Assim, do ponto de vista da construtora, melhor será o resultado final, podendo até superar positivamente as expectativas planejadas. Portanto, o projeto desenvolvido pelas arquitetas tem fundamental importância no processo de construção. Verificamos 
que, nas primeiras etapas de cada empreendimento, as arquitetas apenas atuam como intermediárias entre a diretoria e os projetistas terceirizados, no recebimento e distribuição dos projetos, até que o projeto arquitetônico seja aprovado nos órgãos competentes. Após a aprovação, uma arquiteta passa a ser responsável pelo projeto. São realizadas reuniões de compatibilização entre os projetistas auxiliares, a arquiteta responsável e o engenheiro coordenador do empreendimento iniciado.

o detalhamento executivo de toda obra é a fase seguinte. Os ambientes, áreas externas, fachadas e esquadrias serão definidos a partir de um detalhamento criterioso e elaborado, "o diferencial da empresa", sendo o slogan da construtora. Esta é a etapa mais longa, complexa e a que gera mais conflitos, segundo as arquitetas. Isso acontece por ser uma fase de grandes definições e grande volume de trabalho realizado por apenas uma arquiteta.

Na maioria dos empreendimentos, a construtora também executa um apartamento decorado, com sugestões de mobiliário e decoração. Toda a criação do projeto para esse apartamento é realizada pela Diretora e todo desenvolvimento pelas arquitetas. Este trabalho requer das arquitetas, além da tarefa de desenhar, o contato com os fornecedores. A arquiteta responsável gerencia a aquisição dos adornos, acompanha a execução dos móveis detalhados, instalação, entregas, tudo em um "prazo humanamente inviável", segundo nos relatou uma delas.

Outra tarefa de responsabilidade das arquitetas é a elaboração dos projetos específicos para cada cliente. Após o fechamento do contrato, a Diretora atende cada proprietário que solicitar a personalização do seu apartamento. Essas modificações são repassadas às arquitetas, para o desenvolvimento de projetos específicos do apartamento deste cliente - outro diferencial da empresa, que ficam responsáveis pelo projeto, pelo orçamento, pelo acompanhamento das modificações na Obra e pelos atendimentos posteriores aos clientes. Realizam ainda, em algumas obras, o "rateio". Ou seja, ao final da Obra, os proprietários pagam um valor, que foi estipulado em contrato, para que a construtora possa mobiliar e equipar todas as áreas comuns do Edifício. Da mesma forma que acontece com os projetos, a Diretora define todas as compras e cabe às arquitetas finalizar o processo e acompanhar as entregas e a montagem. Normalmente, é um período estressante, como foi relatado, por ser executado juntamente com a finalização da Obra Civil para a entrega do imóvel aos clientes.

27 Notamos que o início de um novo empreendimento não caracteriza a finalização dos demais. Pudemos constatar que algumas arquitetas, principalmente, as com mais tempo na construtora, chegam a ter até quatro obras sob sua responsabilidade.

\subsection{0 real do trabalho das arquitetas}

28 Nos próximos itens descreveremos em detalhe a atividade de trabalho das arquitetas, revelando aspectos do trabalho desconhecidos e evidenciando como as arquitetas mantêm a produção esperada e as metas diante da discrepância entre o prescrito e a realidade da situação.

\subsubsection{A arte de projetação e o conflito vivenciado pela não criação}

29 A atividade observada é diversificada, variada e complexa, demandando competências técnicas para projetar um ambiente e habilidades relacionais para lidar com clientes, 
fornecedores, engenheiros e estagiárias. Contudo, a arte de criação não faz parte do escopo de atividades das arquitetas, ficando as suas competências artísticas restringidas. Tal função é apenas delegada à Diretora, cabendo a elas apenas dar forma à obra de um outro autor.

O fato de toda a criação ser feita pela Diretora, e não pelas arquitetas, faz com que elas não exerçam a atividade principal de um arquiteto : a de criação. Segundo Rêgo (2001, p. 36) :

Projetação é um processo onde as naturezas cognitivas e criativas convergem de maneira singular. $O$ ato de projetar é por essência uma criação através do domínio do conhecimento específico de uma área do saber - um dar forma a uma matéria específica. Em arquitetura, esse conhecimento é multidisciplinar e até subjetivo, o que torna a relação entre criação e cognição algo ainda mais evidenciado.

31 Conforme observa Almeida (2002, p. 1), a atividade projetual demanda mais do que aptidões técnicas e artísticas, pois "cada projeto consiste em elaborar uma proposta de mediação entre necessidades de sobrevivência e de transcendência de determinado indivíduo ou grupo e o meio ambiente".

32 A impossibilidade de desenvolver o lado criativo causa revolta no grupo de arquitetas. Como nos comprova uma delas, não há reconhecimento de suas competências :

Nunca assinei nem o detalhe de um banheiro de serviço. Nada! Acho que ela [Diretora] não confia na nossa capacidade de criar, só pode ser. Estou meio cansada de ser só desenhista dela. Às vezes uma desenhista ou um estagiário fariam o mesmo que eu faço aqui (Arquiteta).

Há um debate teórico conflituoso sobre os efeitos da informatização sobre o homem, capaz de interferir positivamente ou negativamente para a saúde e segurança dos trabalhadores. De um lado, existe a visão sobre a redução da penosidade do trabalho com a introdução de novas tecnologias, enquanto promotora de bem estar social e facilitadoras das atividades de trabalho (Habermas, 1975 ; Leite, 2003). Por outro lado, alguns autores apontam a intensificação do trabalho com o aparato tecnológico, contribuindo com progressão dos casos de adoecimento relacionados ao trabalho (Merlo, 1997; Abrahão \& Pinho, 2002). Dejours (2008a, p. 37) afirma que as novas tecnologias desestabilizaram a equação entre o trabalho como esforço e o tempo de trabalho, pois "o esforço é descontínuo e a carga física é, agora, é acompanhada agora de uma carga mental", e também psíquica.

34 No caso das arquitetas, ocorreu uma excessiva valorização do computador em detrimento de suas competências. Ou seja, para elas, houve uma "subcarga psíquica" (Wisner,1994), ou seja, após a introdução dos sistemas computacionais para projetos, passam a vivenciar uma maior separação entre concepção e execução do trabalho, ocasionando, no ponto de vista delas, a desqualificação da atividade de arquiteta e o sofrimento por não exercerem a sua imaginação criadora.

\subsubsection{As disfunções encontradas}

35 As representações errôneas do trabalho real dos trabalhadores geram disfunções que precisam ser reguladas pelos trabalhadores, para que os objetivos traçados sejam alcançados (Guérin, Laville, Daniellou, Duraffourg \& Kerguelen, 2001). Para Wisner 
(1994, p. 111) "o inventário das diferenças entre atividades reais e atividades prescritas é extremamente útil para descobrir tudo que é difícil, ou até impossível de realizar no trabalho prescrito ou que foi mal compreendido".

Durante a análise, foi observado como uma ordem simples pode gerar revolta e como esse vem carregado de símbolos que somente foram sendo compreendidos ao longo da pesquisa. Por exemplo : porque o fato da Diretora ligar para o departamento chamando uma arquiteta gera irritabilidade?

Ficou constatado que o acúmulo de atividades extras atrapalha o andamento do trabalho da arquiteta. Os cronogramas elaborados ignoram a atividade real de cada arquiteta, a falta de estrutura da equipe, as variabilidades enfrentadas e subestimam o tempo necessário para a realização de cada etapa do projeto.

$\mathrm{O}$ cronograma é feito imaginando que a gente só tem isso para fazer. Como se eu chegasse no trabalho, pudesse desenhar o dia todo e ninguém me interrompesse. Que é só dar um comando para o computador e ele faz tudo sozinho. Estou a manhã inteira aqui resolvendo coisas bobas, mas que se eu não fizer a obra pára e ainda não desenhei uma linha. Meu peito até está doendo, vou ficando angustiada. Chego a tremer ! (Arquiteta).

Além destas tarefas prescritas, as arquitetas assessoram o andamento dos projetos na obra. Apesar do andamento ser de responsabilidade dos engenheiros, é importante a presença das arquitetas na obra para auxiliá-los nessa tarefa e esclarecer dúvidas.

Outra tarefa, não prescrita às arquitetas, e que demanda muito tempo, é o apoio feito à todas as atividades da empresa, relacionadas à Diretora, como o Departamento de Marketing e de Orçamento. Por exemplo, montagem de material publicitário para vendas e divulgação, tomada de preços para um determinado material, além de assessoria nos orçamentos de clientes.

40 Os cronogramas elaborados também não consideram o fato de que toda a tomada de decisão, no departamento de arquitetura, se concentra somente em uma pessoa, a Diretora. Ela é responsável por diversas funções, restringindo o tempo disponível da mesma para o departamento de arquitetura, gerando demora na liberação das informações, atrasando o trabalho das arquitetas.

41 Segundo a arquiteta mais antiga do setor, nenhum dos arquitetos atuais, ou mesmo os que já passaram pelo setor, tinham qualquer autonomia de decisão. "Até para respirar tem de pedir permissão [risos]". Para ela, submeter toda e qualquer resolução à aprovação da Diretora "trava" o desenvolvimento do trabalho e gera muitos atrasos, principalmente quando decisões simples, solicitadas com urgência pela obra, poderiam ser solucionadas em tempo real pelas próprias arquitetas.

42 A experiência acumulada ao longo dos anos permite a tomada de certas decisões sem comprometer o resultado final e sem modificar o padrão adotado pela Diretora. A verbalização abaixo demonstra o conflito vivenciado pelas arquitetas quando o seu trabalho é atrasado devido à falta de tempo da Diretora :

Toda vez que eu estou na sala dela [Diretora], sou interrompida. E ainda por cima, acontece de eu sair de lá [sala da diretoria] sem a resposta que preciso. Tudo passa na nossa frente. Ela [Diretora] atende telefone o tempo todo. Só que ninguém vê isso, não vê que perdi tempo. Foram duas horas perdidas, esperando por ela [a Diretora] e tenho que compensar depois, me virar para dar conta de tudo e sem ganhar hora extra (Arquiteta). 
Diversas vezes foi observado que as arquitetas, ao serem chamadas para uma reunião na sala da Diretora, foram interrompidas por telefonemas, entrada de outras pessoas e mesmo a ausência da Diretora na sala, fato este muito freqüente, segundo elas. Esta interrupção durante a reunião, aumenta o tempo total gasto para resolução de questões pendentes e discussão de projetos. Além disso, não é raro elas retornarem novamente à sala da Diretora devido ao cancelamento ou adiamento da reunião.

Foi constatado também que os diretores, em visitas às obras, fazem modificações nos projetos e essas não são repassadas ao departamento, o mesmo sendo feito pelos engenheiros da obra. Essa situação leva à perda do controle de gerenciamento dos projetos pela arquiteta, aumentando o retrabalho :

Se o negócio está errado é só me dizer ! Eu não ligo de corrigir, o que não dá é para ficar sendo a última a ter conhecimento das modificações. Se reutilizar o detalhe antigo, o erro vai se repetir. E se o projeto manda fazer de um jeito, é porque a gente pensou muito. Não é para simplesmente eles [os diretores] mudarem tudo. Assim não precisariam da gente (Arquiteta).

No momento de revisar o projeto ou da elaboração do as built (projeto assim como foi construído), a coleta de dados será trabalhosa, com maior dispêndio de tempo. De fato, observa-se que o real executado na obra não condiz com o que foi detalhado pela arquiteta. Além disso, segundo as arquitetas, elas utilizam rotineiramente detalhes anteriores para novas obras. Dessa maneira, a falta de comunicação entre os dirigentes e as arquitetas, sobre as modificações nos projetos e da elaboração de um as built, faz com que os mesmos erros se perpetuem :

Isso é muito comum. Outro dia mesmo por causa de um erro, todas as bancadas precisaram ser recortadas, o que gerou gastos, perda de tempo e o resultado final ficou uma porcaria. Eu perdi meu tempo tendo que revisar os detalhes. Fiquei com raiva. $O$ engenheiro me disse que o detalhe estava errado, mas ele viu e corrigiu a tempo. Só que não passou para gente essa modificação. Como é que eu ia adivinhar ? (Arquiteta).

o departamento de engenharia trabalha conjuntamente com o de arquitetura nos empreendimentos da empresa. 0 primeiro é responsável pela execução dos projetos e o segundo pela elaboração e coordenação dos mesmos. Desta forma, cada projeto necessita do suporte técnico desses dois setores.

Como foi dito anteriormente, a arquiteta atua como intermediária da obra e da diretoria. Essa posição gera alguns conflitos, pois devido à falta de autonomia na resolução de problemas e tomada de decisões, a arquiteta parece ser apenas um meio de comunicação entre as partes, gerando uma espécie de "burocracia necessária" como diz a Diretora. Para poder gerenciar todas as atividades, ela utiliza essa "peneira". A arquiteta discute com o engenheiro, recolhe as dúvidas que são levadas à Diretora. Constatou-se que diversas dúvidas acumuladas ao longo do dia poderiam ser esclarecidas rapidamente sem interromper o trabalho da arquiteta, caso o engenheiro tivesse contato direto com a Diretora - que é quem dá as definições - ou se, principalmente, as arquitetas pudessem buscar soluções para os problemas.

Outro fator que gera atrasos no desenvolvimento dos projetos é a dificuldade de obter as informações necessárias para o desenvolvimento do projeto. A atividade das arquitetas requer informações técnicas para o desenvolvimento dos projetos, desde a concepção do projeto por parte da Diretora até a situação da obra, pelo engenheiro. A 
não organização das informações e a dificuldade de acesso causam atrasos no processo. Nas entrevistas, fica claro que essa co-dependência causa conflitos entre os setores e atrasos na obra. A falta de um trabalho em equipe, a dificuldade de acesso às informações por falta de comunicação, tanto por fatores de disponibilidade quanto por dificuldades de relacionamento entre as partes, afetam o trabalho, como comprova o relato abaixo :

Ontem eu liguei o dia inteiro para a obra só para perguntar se já tinham sido encomendadas as pedras para eu começar o detalhamento e não tive resposta. Atrasei o meu trabalho. Não consegui definir qual seria o detalhe e o pior, acumulei atividade para o outro dia. E o que poderia ser feito em duas horas, só fui começar hoje. Mas, pode ter certeza que ninguém vê isso (Arquiteta).

Mais um aspecto observado está relacionado às tarefas de apoio à Diretora. Ficou constatada através das observações, podendo ser comprovado na verbalização a seguir, a grande quantidade de vezes que a arquiteta interrompe sua atividade para realizar tarefas simples, tais como: impressão de documentos, coleta de assinaturas em projetos, preenchimento de documentos e xerox, ou mesmo atividades particulares da Diretora.

Eu perco tempo com muita coisa que uma secretária poderia fazer, ou um ajudante, ou até mesmo uma estagiária. Cotar preços. Entregar documentos, xerocar papéis, medir a obra várias vezes, ir até as lojas conferir o que foi comprado. Tenho que fazer mil coisas ao mesmo tempo! (Arquiteta).

50 A dificuldade de comunicação gera também outros conflitos entre a arquiteta e os engenheiros causados pela má interpretação das informações. É comum ocorrer um mal entendido em algum projeto e este não ser esclarecido. Neste caso, o engenheiro executa o detalhe da maneira que ele "julgar melhor", muitas vezes não coincidindo com a opinião da arquiteta :

Se foi feito um detalhe, ele foi muito pensado. É claro que existem mil opções, mas escolhemos a que foi melhor. Às vezes, a solução que o engenheiro deu na obra, a gente já tinha pensado e desistido dela por causar outros problemas que nós antecipamos e ele não (Arquiteta).

51 Constatamos ainda que, a falta de organização do armazenamento das informações ao longo dos anos faz com que hoje, agravado pela alta rotatividade do grupo de arquitetas, não exista uma memória registrada dos processos e procedimentos realizados na empresa.

Cada vez que uma arquiteta deixa a empresa, é como se toda a informação que ela dominasse fosse perdida, por não existirem registros. Um hábito descrito pela arquiteta mais antiga como "errado" é o fato de não existir um modelo da Construtora a ser seguido, como forma de padronização. A interpretação e tradução de padrões diferentes se fazem necessárias. Cada arquiteta que entra cria seu próprio padrão dificultando a comunicação entre a equipe e aumentando o tempo gasto para realizar um trabalho. 


\subsubsection{A penosidade do ambiente : ruído e adensamento} trabalho - demanda inicial - e as possíveis conseqüências para os trabalhadores. A arquitetas queixam-se constantemente do ruído no ambiente de trabalho. A intolerância ao ruído pode ser a primeira manifestação de distúrbios provocados pelo trabalho ; é fácil ser percebida pelos trabalhadores sendo mais facilmente exteriorizada através de pedidos de silêncio. Sabemos que o ruído exerce forte influência sobre o desempenho humano no trabalho, podendo gerar problemas de irritação, nervosismo, dificuldade de concentração e de raciocínio, maior incidência de erros e queda na produtividade (Santos \& Fialho, 1995).

De acordo com a Norma Regulamentadora de Ergonomia Brasileira (BRASIL/MTE, 2002, p. 37) "as condições ambientais de trabalho devem estar adequadas às características psicofisiológicas dos trabalhadores e à natureza do trabalho a ser executado". Para análise da penosidade do trabalho, é imprescindível a avaliação da percepção dos trabalhadores sobre o desconforto causado pelo ruído, bem como a análise das atividades desenvolvidas e não apenas a avaliação quantitativa dos resultados e estimativa do nível de exposição pessoal diário. Entendemos, portanto, que o ruído no ambiente de trabalho não deve ser avaliado somente por sua capacidade de provocar lesões no aparelho auditivo, tal como a perda auditiva, mas como a perturbação passível de prejuízo ao bom desempenho do trabalho. Desta maneira, buscamos analisar as dificuldades enfrentadas pelas arquitetas diante da necessidade de um ambiente tranqüilo e silencioso para a execução da tarefa planejada.

Os resultados das observações realizadas indicaram que, em geral, os horários de pico correspondem aos momentos de maior aglomeração de pessoas no setor, mostrando haver uma variabilidade do nível de ruído. Os períodos entre 11 e 12 horas e depois da cinco da tarde, correspondem aos intervalos com maiores níveis de ruído. $O$ atual sistema de horário de entrada e saída das arquitetas é visto como um fator que contribui para a variação dos horários de pico. Conforme foi constatado, à medida que as pessoas chegam ao setor para iniciar a jornada de trabalho ou para retornar do horário do almoço, o desconforto, causado pela ação de conversas e por outras fontes de ruídos, vai aumentando. Este processo pode ser depreendido no discurso abaixo :

No meio da manhã e no final da tarde, isso aqui ferve ! Tem gente entrando e saindo, gente falando alto no telefone, gente batendo papo. Todo mundo ao mesmo tempo no setor. Aí acabo ficando no horário do meu almoço para poder ter sossego, paz para pensar e para analisar os projetos. Fico também à noite! (Arquiteta).

Segundo nos relatou a Diretora do setor, os problemas de ruído poderiam ser evitados caso as arquitetas tomassem conhecimento sobre "regras de conivência em grupo".

É pertinente mencionar uma tendência importante e que age como agravante para o problema do ruído. Trata-se do ambiente de conversação. Verificou-se que as conversas informais somam-se às conversas que fazem parte do processo de trabalho de forma a difundir o som por todo o pavimento. O próprio layout local tem favorecido a propagação sonora devido, principalmente, à falta de barreiras físicas. Naturalmente, muitos desses problemas não podem ser equacionados. É razoável supor que os problemas de ruídos tornam-se mais complicados quando a própria fonte é um gerente ou coordenador. Neste caso, as arquitetas, diante da diferença de hierarquia, não 
encontram formas de exporem o desconforto gerado pelo esquecimento do celular de um gerente ou pela altura da voz de um diretor.

Como pudemos observar, a necessidade de colocar um número maior de pessoas em um mesmo ambiente de trabalho demandou do departamento uma série de alterações no ambiente físico de trabalho existente, tais como: redução dos espaços de circulação, retirada de divisórias e armários, realocação das mesas e gaveteiros, etc. No mesmo espaço, trabalhavam, inicialmente três arquitetas e uma estagiária. Hoje, o mesmo ambiente, é ocupado por cinco arquitetas e, no mínimo, duas estagiárias.

Verificamos que o espaço sob a mesa passou a ser utilizado para a colocação do gaveteiros volantes após a modificação do espaço físico. Devido à redução da largura dos corredores, os gaveteiros, que antes ficavam ao lado da mesa em várias estações de trabalho, passaram a ocupar o espaço necessário para a livre movimentação das pernas. Nota-se que a rigidez do uso da estação de trabalho impede a utilização das extremidades da mesa para outras atividades. As arquitetas encontram dificuldades para girar a cadeira, adotando, freqüentemente, a postura de rotação de tronco para realizar tarefas que não estejam relacionadas ao uso do microcomputador, tais como : escrever; analisar documentos; atender pessoas, etc. Isso faz com que, muitas vezes, batam as pernas ou joelhos nos cantos dos gaveteiros. A literatura aponta que o layout da estação de trabalho deve garantir a flexibilidade na utilização de toda a superfície, permitindo que o trabalhador mude facilmente de posição de acordo com a atividade que está exercendo. A largura do vão deve ser de pelo menos 70 centímetros ou mais, caso se necessite a rotação e deslocamento do funcionário quando este estiver sentado (Brandimiller, 1997).

Outro fator identificado foi que as arquitetas utilizam o telefone como principal instrumento de comunicação com os outros setores da empresa, obras, fornecedores e clientes. Esta forma de trabalho, apesar de ser imediata, interrompe, muitas vezes ao dia, o fluxo de concepção e execução. Durante as observações sistemáticas, constatou-se que no período de uma hora, uma arquiteta chega a receber até 10 ligações. Fato esse, agravado pela falta de um ramal para cada uma delas. Tal situação interrompe o processo de trabalho de duas pessoas: da que atende ao telefone e daquela que para quem se destina à ligação.

61 Tais interrupções, apesar de fazerem parte do trabalho das arquitetas, atrapalham a atividade principal de projetação que exige concentração.

As conversas telefônicas são apontadas com uma das principais fontes de ruído, incluindo o volume do toque. Como podemos verificar nas verbalizações abaixo, algumas arquitetas chegam a levantar do posto de trabalho para desligar o celular esquecido sobre a mesa.

Imagina você trabalhando, pensando em algo importante. Aí o telefone celular de outra pessoa começa a tocar alto. Sabe àqueles toques musicais, altos, com música de péssima qualidade. Então, como você quer que depois eu volte a me concentrar? Já tive problema com colegas porque levantei e fui desligar o telefone celular esquecido na mesa (Arquiteta).

63 Parte dos telefonemas poderia ser evitada caso existisse uma triagem das ligações ou se as arquitetas deixassem de ser intermediárias entre obra e diretoria, pois elas não possuem autonomia para responder as dúvidas passadas a elas. 

momento. Isso interrompe o fluxo de trabalho e tira a concentração, como nos foi relatado:

Depois das cinco horas ninguém mais trabalha aqui. É um entra e sai de gente, uma falação que é difícil. Aí eu desisto de fazer qualquer coisa que precisa de concentração. Cada engenheiro sai da sua obra e vem aqui tirar dúvidas. Não existe uma sala de reuniões. Tudo acontece neste local (Arquiteta).

As atividades desempenhadas pelas arquitetas requerem solicitação intelectual constante, pois demandam concentração, memória de longo e curto prazo, solução de problemas, cálculos, análise de projetos e tomadas de decisão. Nestes casos, um cenário com tais contornos, como um ambiente barulhento - mesmo que este não ultrapasse o limite permitido pela lei - amplifica o desconforto tornando a atividade penosa, pois perturba um trabalho que requer atenção, o que pode provocar uma alta carga de trabalho. $\mathrm{O}$ tom polifônico de um celular, por exemplo, mesmo com o volume baixo, pode constituir “a gota d'água que torna o trabalho insuportável” (Wisner, 1994, p. 49).

Com efeito, o conceito de penosidade introduzido pela ergonomia, ao invés dos conceitos de insalubridade e periculosidade geralmente utilizados pela saúde ocupacional, relaciona-se com o de sensação de conforto segundo a percepção do próprio trabalhador (Assunção \& Lima, 2003). Uma situação penosa repousa sob condições de trabalho que podem causar sofrimento, incômodo e demandam esforço sobre os quais, normalmente, o trabalhador não tem controle (Sato, 1993). Não é difícil encontrar queixas que aludem esse problema :

Chego a gritar para conversar com meu marido depois de um dia inteiro de trabalho. Falo alto! Minha família me pede para baixar a voz. Tenho tido muita dor de cabeça, sensação que saí de uma festa. Já coloquei fone de ouvido, como se estivesse ouvindo música para tentar diminuir o barulho. Meu corpo dói todo ! (Arquiteta).

Uma questão igualmente importante e que merece ser destacada é a articulação de uma estratégia coletiva tácita para contornar o problema quando o ruído torna-se insuportável. Observa-se que algumas arquitetas começam a demonstrar o desconforto vivenciado através de solicitações de silêncio, pelo uso do "psiu" (expressão culturalmente utilizada no Brasil para pedir silêncio). Entretanto, devido à ineficácia que muitas dessas estratégias tem demonstrado, várias pessoas acabaram por aprimorá-las deliberadamente. Neste caso, algumas arquitetas passaram a escutar música em fones de ouvido e, à medida que o nível de ruído vai aumentando, segundo nos relataram, elas aumentam também o volume do som da música.

Finalmente, pudemos perceber que diversos trabalhadores saíam do ambiente de trabalho a fim de buscar locais mais isolados para a realização de seu trabalho. Entretanto, essa forma de regulação só é profícua para algumas arquitetas, principalmente para aquelas que visitam com maior freqüência os canteiros de obra.

A despeito da pertinência ou eficácia de tais estratégias, identificamos que as regulações e formas de defesa desenvolvidas pelos trabalhadores buscam criar um espaço individual onde seja possível realizar tarefas que demandem concentração e evitem situações de sobrecarga física, mental ou afetiva. Constata-se, neste caso, a 
necessidade de espaços potencialmente eficazes ao convívio social e ao perfeito desenrolar do trabalho.

Podemos afirmar que, o agrupamento de pessoas em um mesmo local, por nós denominado de adensamento, além de ser mais uma fonte de ruído dificulta, também, a concentração das arquitetas. É importante salientar que nem todas as situações são igualmente nocivas. Cada um reage singularmente a uma situação penosa, dado o caráter idiossincrático de cada indivíduo, como por exemplo, histórias profissionais e pregressas distintas, submissão a condições de vida e extraprofissional particulares, posse de características fisiológicas particulares (Guérin, Laville, Daniellou, Duraffourg \& Kerguelen, 2001).

Guardadas essas constatações, observa-se que as interrupções constantes causadas pelo ruído podem ser mais penosas para uns do que para outros. Algumas arquitetas não relataram nenhum tipo de desconforto causado pelo ruído ou pelas modificações causadas pelo adensamento de pessoas. Para elas, a situação não é percebida como nociva. Entretanto, achamos importante mencionar a fala de uma entrevistada : "Não sei se me incomoda ou se já me acostumei".

Tarefas freqüentemente interrompidas ou descontinuadas induzem a uma autoaceleração mental e aumentam ainda mais a quantidade de trabalho a ser realizada no mesmo tempo, bem como a densificação do trabalho, pois obrigam o trabalhador a retornar o fio do trabalho toda vez que é interrompido, fazendo com que às vezes refaça toda a seqüência ou adie para mais tarde a tarefa começada, "o que por vezes significa ter que começar a tarefa toda de novo" (Wisner 1994, p. 49). Desta percepção surge, naturalmente, a visão de que sinais de sofrimento psíquico podem estar atrelados a algumas situações específicas de trabalho onde as tarefas são freqüentemente interrompidas (Wisner, 1994, p.11). Alguns depoimentos auferem legitimidade a esse argumento :

Está cada vez mais difícil. Me acho chata! Preciso me concentrar, estou no meio de um pensamento e alguém me chama. Tem hora que é por causa do trabalho tem hora que não tem nada a ver. Sei que é importante relaxar, conversar com os colegas, jogar conversa fora! Mas, como cada uma tem um ritmo, muitas vezes, quando o grupo quer comentar da novela ou falar alguma coisa de interesse comum, eu estou pensando (Arquiteta).

\subsubsection{0 controle e a competitividade}

73 Além dos constrangimentos descritos, um outro fato relatado pelas arquitetas é o de serem vigiadas constantemente. A forma como o espaço é organizado permite que elas sejam controladas pela Diretora e, ao mesmo tempo, controlem visualmente o trabalho uma das outras.

A sala da Diretora possui uma janela, que possui uma persiana e um vidro especial que permite que a diretora as veja constantemente, mas sem que as arquitetas possam vêla. A existência dessa janela é vista como elemento de vigia e imposição, pelas arquitetas :

Não agüento mais trabalhar de costas para a Diretora e ainda por cima com a persiana aberta. É horrível ter alguém nas minhas costas enquanto trabalho. Sendo vigiada, analisada e controlada. Não olho nem meu e-mail particular porque sei que posso ser repreendida. Parece uma prisão! (Arquiteta). 
Muitas vezes, a Diretora telefona para as arquitetas para questionar o que elas estão fazendo ou faz gestos da sala dela para restringir conversas ou telefonemas pessoais. 0 tempo não produtivo é controlado constantemente pela Diretora, ignorando as especificidades de cada uma das arquitetas, buscando constantemente ditar o ritmo de trabalho. O que, nas palavras de Thompson (1998, p.298), significa que em uma sociedade capitalista "todo o tempo deve ser consumido, negociado e utilizado ; é uma ofensa que a força de trabalho meramente passe o tempo".

Essa forma de hierarquização rígida e a adoção de normas disciplinares fortemente coercitivas, além de constrangedoras, impedem a expressão de queixas e reinvidicações. $O$ trabalhador "se sente engasgado pelas palavras que não pode deixar fluir de sua garganta” (Silva, 1994). O extrato abaixo ilustra esse sentimento :

Vou ficando calada, vou engolindo, mas tem uma hora que a minha paciência se esgota. Não tenho que agüentar meu chefe mandando eu desligar o celular, ou falar baixo! Mas, um dia que eu não venho trabalhar a obra não anda! (Arquiteta).

77 As arquitetas trabalham, portanto, sob a vigilância constante da Diretora que pode "saber onde e quando encontrar os indivíduos, instaurar as comunicações úteis, interromper as outras, poder a cada instante vigiar o comportamento de cada um, apreciá-lo, sancioná-lo, medir as qualidades ou os méritos" (Foucault, 1994, p. 131).

Ademais, a atual política de rastreabilidade do setor de informática da empresa verifica semanalmente o histórico de navegação da Internet, bem como da área de trabalho de cada uma das arquitetas, restringindo o uso pessoal da Internet durante a jornada de trabalho.

Agora nem mais posso entrar no Messenger. Não adianta explicar que utilizo como ferramenta de trabalho, porque faço contato com as empresas terceirizadas, com clientes, com engenheiros que estão nas obras ou arquitetas que prestam serviço para gente. Tratam-me como se não fosse capaz de decidir o que é certo ou errado. Resolveram proibir e pronto! Tentei argumentar e me falaram que não tinha jeito (Arquiteta).

79 A tecnologia da informática permite também o controle de cada ato de trabalho e de sua duração, graças à precisão dos relatórios de informações. O tempo que cada arquiteta passa conectada ao sistema (logada) é controlado, desconsiderando, neste caso, o tempo gasto nas obras, as horas para levantamento de orçamento e outras tarefas a elas demandadas que não requerem o uso do terminal. Algumas chegam a relatar que deixam o sistema "logado", mesmo quando não estão presentes, para não terem que justificar o tempo não despendido em frente ao terminal do computador, apesar de não receberem pelas constantes horas-extras.

Não obstante, mesmo diante da ausência da Diretora, permanece o esquema de vigia contínua entre as arquitetas. A disposição das mesas permite que a tela do computador de cada uma das arquitetas, possa ser vista por pelo menos por outras duas arquitetas. Neste caso, além do controle disciplinar da Diretora, e do setor de Informática, há simultaneamente o controle do próprio grupo. O grupo exerce pressão sobre os indivíduos, o que Malaguti (1996) denomina de controle "corpo a corpo". É comum na fala das arquitetas relatos repreendendo o exercício de atividades "extraprofissionais" por suas colegas durante a jornada de trabalho, desde conversas em salas de bate-papo 
ou Messenger até o uso da jornada de trabalho para desenvolver projetos autônomos contratados por terceiros. Diante do controle do grupo, algumas arquitetas preferem trabalhar em horários diferentes para que, na fala delas, não sejam interrompidas constantemente e nem vigiadas passo a passo.

Cabe aqui discutirmos como a atual política da empresa de avaliação individual do desempenho corrobora com a competição acentuada dentro do setor de arquitetura. $\mathrm{Na}$ grande maioria dos projetos, cada arquiteta fica responsável por uma obra, não sendo necessário o trabalho em equipe. Espera-se que ela cumpra individualmente o cronograma, porém, para que isso ocorra, chegam a trabalhar feriados e nos fins de semana, fora às horas-extras semanais, pois :

"Não preciso que me mandem fazer, sei que é minha responsabilidade e se não fizer irão cobrar de mim, por isso faço minha agenda, levo trabalho para casa e fico até mais tarde sempre, porque só assim dou conta de tudo!" (Arquiteta)

São controladas por meio dos objetivos e resultados, neste caso, conforme explica Zarifian (2002, p. 27), "o assalariado deve prestar contas regularmente dos seus resultados, e os objetivos que lhe são atribuídos podem ser rapidamente reatualizados". Neste modelo de gestão, é valorizado a auto-superação e o alcance dos objetivos individuais, valorizando o sucesso individual. Dejours (2008a, p. 80) afirma que "a avaliação individualizada gera condutas de concorrência generalizada entre os trabalhadores que chegam até a deslealdade".

Diante das metas contínuas, as arquitetas mantêm uma rotina intensificada de trabalho, "que nunca cessa", corroborando com o aparecimento de "patologias de sobrecarga". Neste caso, a articulação entre a avaliação individualizada e as tecnologias informatizadas que permitem a rastreabilidade levam "muitos trabalhadores a perderem totalmente a possibilidade de controlar o acréscimo de sua carga de trabalho, e por causa disso adoecem" (Dejours, 2008a, p. 81).

Constata-se que o sofrimento psíquico e a cobrança são mais intensos para a arquiteta mais antiga, devido a todo o processo de transformação no qual ela esteve inserida. Ela apresenta queixas de dores nos membros superiores há mais de um ano e sente grande ansiedade e sofrimento por não mais poder criar os projetos e por ainda não ter procurado outro emprego para deixar o atual. Nos dizeres dela :

Sinto dor no corpo todo, mais nos ombros. A dor sobe para o pescoço e às vezes formiga. Mas, a dor mais forte é no peito, ela não passa, já procurei cardiologista, psicólogo e psiquiatra nos últimos meses, eu sei que dói porque fico nervosa, uma pilha, com tanta cobrança e falta de reconhecimento. Quero muito arrumar outro emprego, para cuidar de mim, mas também não procuro! (Arquiteta).

Apesar do sofrimento causado pela densificação do trabalho, a arquiteta mais antiga, mesmo colocando em risco a sua saúde, não deixa, segundo ela, o processo parar de funcionar, pois :

A obra não pode parar! A cobrança dura só vem para mim, já que as outras meninas são novatas. Só eu que tenho o meu emprego constantemente colocado em jogo, se tudo não der certo. Minha saúde e minha vida que se danem. Poucas vezes recebi um muito obrigado por ter terminado a obra a tempo. Mesmo sem o reconhecimento da Diretoria, o que é muita ingratidão, 
eu olho com orgulho para o prédio, sei que só terminou porque eu segurei o

batente! (Arquiteta). arquiteta com mais tempo na empresa permanecer trabalhando, mesmo diante do desgaste físico e mental. Para ela, o reconhecimento não é material nem financeiro, diz respeito à realização pessoal. Entretanto, a ausência de reconhecimento pela Empresa torna o enfrentamento da situação mais penoso, podendo configurar-se em ameaça à saúde mental (Silva, 1994).

A discussão acima nos mostra formas de controle da "sociedade disciplinar", nos termos de Foucault (1994), como a vigilância da Diretora pela janela, a rastreabilidade dos dados, o próprio layout do ambiente. Por outro lado, há elementos da "sociedade de controle", que segundo Zarifian (2002, p. 23) faz parte da sociedade moderna onde "nunca se arremata coisa alguma: tudo muda, modula-se e remodula permanentemente, tanto o conteúdo do trabalho como as metas ou as aquisições cognitivas do indivíduo". Trata-se, de acordo com Zarifian (2002, p. 27), do "controle do engajamento". Tal processo de modulação do engajamento subjetivo ocorre a partir do "próprio assalariado quem irá acionar sua atividade de trabalho (assalariado) e modular os momentos em que o fará. Mas isso supõe um forte compromisso de sua parte: ele deve por si mesmo se obrigar a fazê-lo".

\subsection{As repercussões para a saúde das arquitetas - patologias da solidão}

Procuramos identificar os tipos de documentos de saúde disponíveis e as formas de compilação dos mesmos. Constatamos a carência de dados de saúde pregressos que pudessem ser utilizados na identificação do perfil de morbidade do grupo de arquitetas. Os poucos dados existentes na empresa referem-se às faltas legais (casamento, óbito, doação de sangue, acompanhar familiar, acordo sindical, etc) e as médicas (atestado médico interno e externo) por períodos menores que 15 dias. A partir das entrevistas realizadas com as arquitetas, foi possível identificar quais casos de afastamentos poderiam estar relacionados ao trabalho. Nos interessava, a localização corporal, os tipos de queixas percebidas pelas arquitetas, os medicamentos utilizados e as causas dos afastamentos.

Das cinco arquitetas, quatro tomam diariamente medicamentos para depressão e ansiedade. Uma encontra-se em tratamento para gastrite crônica. Todas relataram dores musculares na região da coluna cervical e dos membros superiores, com sintomas importantes de parestesias (sensações cutâneas subjetivas frio, calor, formigamento, pressão) ao longo da jornada de trabalho. Destas, duas estavam há mais de um ano em tratamento fisioterápico.

90 Três arquitetas queixaram de dores de cabeça intensas e uma arquiteta afirmou que vinha sofrendo picos de pressão alta durante a jornada de trabalho, principalmente, durante as reuniões, quadro já controlado pelo uso contínuo de medicamentos para hipertensão.

91 Entre o grupo de ex-arquitetas, duas explicaram que além das altas cargas de trabalho, as dores musculares constantes foram decisivas para que pedissem demissão da 
empresa. Uma das ex-arquitetas já passou por duas cirurgias ortopédicas para redução de dores na região cervical.

Por outro lado, quando questionamos ao grupo que permanece na ativa quais motivos levaram a saída das outras arquitetas, é comum apontarem questões individuais e não apenas problemas organizacionais : "tal arquiteta não tinha estrutura para agüentar nosso ritmo", "fulana tem problemas psicológicos, precisa se tratar, para entender que o mundo é assim, que ela não vai mudar nada !" ou "tem gente que é muito molenga, que não vê que para ficar aqui tem que ser bom, tem que se entregar de corpo e alma".

A competição do grupo e as formas de avaliação individualizada do desempenho desestruturam as estratégias coletivas, reduzindo a solidariedade, transformando a dor de cada uma em uma dor só, em "patologias da solidão". Fica claro no depoimento abaixo como a competição e a individualização banalizam o sofrimento do outro.

Se eu soubesse que para reduzir meu trabalho era só passar mal na frente da Diretora, já tinha feito! Na ora de mostrar serviço, que pode pegar o melhor prédio, a pessoa passa na frente, parece ser o máximo. Conta vantagem é perfeitinha! Mas aí na primeira dificuldade, passa mal e todos têm que ajudá-la, parar tudo que está fazendo, atrasar seu projeto e quem fica com o mérito ? Mas, se eu tiver atrasada ninguém vai me ajudar porque não fiz cena de frágil (Arquiteta).

Conforme explica Dejours (2008b, p. 19), "quando se está só, abandonado pelos demais, é psicologicamente muito mais difícil suportar a injustiça do que quando se conta com a cumplicidade dos colegas".

Mesmo que as queixas e as doenças descritas pelas entrevistadas não estejam unicamente relacionadas ao trabalho, nem sejam de origem ocupacional, este quadro pode ser um importante indicador da nocividade do trabalho para o grupo estudado. Apesar do desconforto percebido, as arquitetas afirmam que raramente se ausentam do trabalho, mesmo quando doentes ou com dores musculares intensas devido ao acúmulo de serviços, pela competitividade interna e por medo de perderem o emprego. Para Dejours (1998), o medo do desemprego e de não corresponder às "exigências" da competitividade, transforma a constituição das identidades coletivas, resultando na redução das reações de indignação, de cólera e de mobilização coletiva. A falta de reação perante a adversidade social e psicológica causada pela nocividade das condições de trabalho aumenta a carga de trabalho e a fadiga dos que continuam trabalhando e contribui para a degradação progressiva das relações de trabalho, criando uma situação favorável a mudanças do perfil patológico das populações trabalhadoras.

\section{Relações entre o sofrimento identificado e os aspectos organizacionais}

96 A análise da atividade da arquiteta permitiu a formulação de um diagnóstico a partir dos resultados encontrados, possibilitando "apontar os fatores a serem considerados para permitir a transformação" (Guérin, Laville, Daniellou, Duraffourg \& Kerguelen, 2001, p. 175).

97 A importância do departamento não se reflete em sua estrutura. Como já foi dito, não existe uma gerência atuante, subordinada à diretoria, que poderia agir como 
intermediária autônoma. Além disso, o número de pessoas não é suficiente para o volume de trabalho, o que gera sofrimento como pode ser comprovado em grande parte das verbalizações.

Não vou dar conta. É coisa demais. Ela deveria passar uma semana aqui, para ver como isso aqui funciona (...) Ela ia começar a ver que é impossível dar conta e fazer tudo que ela quer. No final, eu tenho que dobrar para terminar tudo. Já perdi a conta de quantas vezes (Arquiteta). de 90 , o ritmo de trabalho era diferente. Os projetos eram desenhados à mão, em pranchetas, e, cada arquiteta possuía maior capacidade de criação e autonomia, sendo responsável desde a concepção até a execução final do projeto. Contudo, com o desenvolvimento de softwares de desenho e de projeto, houve, segundo as arquitetas que acompanharam todo o processo de transição, a intensificação do ritmo de trabalho, agora ditado por uma máquina, bem como a redução da capacidade de criação. A esse respeito, Bassalo (1995) explica que, para alguns arquitetos, o uso do computador descaracteriza o aspecto poético e artístico do ato da concepção arquitetônica e, além disso, pode provocar o cerceamento da liberdade de criação no ato de com ele projetar. Por outro lado, é evidente que tais ferramentas facilitam o trabalho do arquiteto, aumentam a qualidade do produto final, são mais precisos e reduzem o tempo entre concepção e execução de um projeto arquitetônico. Mas, também aumentam a carga 
física e psíquica de trabalho, intensificam as formas de controle e, no caso específico estudado, corroborou com a abolição do poder de criação das arquitetas, forçosamente transformadas, não somente pela máquina, mas também pela organização do trabalho adotada, em desenhistas, sem mais o poder de concepção; apenas executoras dos projetos criados e elaborados pela Diretora do setor.

Segundo Wisner (1994), situações específicas de trabalho podem estar ligadas a sinais de sofrimento, tais como: o trabalho sob exigência de tempo, situações de conflito, tarefas freqüentemente interrompidas e atividades que induzem a uma auto-aceleração mental.

Com a informatização dos serviços e com a expansão do mercado de construção civil nos últimos anos, a construtora pôde aumentar o número de obras realizadas simultaneamente. Apesar de ter ocorrido o aumento do número de arquitetas no setor, de três para cinco, houve tanto o aumento do número de projetos simultâneos sob a responsabilidade de uma arquiteta quanto do grau de especificidade e detalhamento de cada projeto.

Umas das queixas mais recorrentes são as cobranças constantes para o cumprimento dos cronogramas planejados pela Diretora que desconsidera a atividade real das arquitetas e todos os condicionantes existentes. As arquitetas vivenciam diariamente a pressão pela entrega dentro do prazo dos projetos. É comum a Diretora culpar pessoalmente cada arquiteta pelo atraso dos projetos, desconsiderando os reais motivos que as impediram de executar a tempo as tarefas prescritas.

106 A análise do sofrimento psíquico requer um estudo mais aprofundado sobre a análise das práticas sociais e dos indivíduos que estão nela inseridos. É preciso olhar para a situação de trabalho estudada para compreender como os seus elementos subjetivos, sociais e organizacionais estão contribuindo para a degradação da saúde mental das arquitetas.

Acreditamos que as funções delegadas a cada uma das arquitetas devem ser replanejadas, de acordo com suas competências, para que a atividade real seja realizada sem o comprometimento da saúde. A partir do momento em que a atividade real e os constrangimentos vivenciados por elas passarem a ser do conhecimento de todos, cronogramas viáveis poderão ser planejados.

108 Assim, também será possível realizar o redimensionamento da equipe, em caso de necessidade, para que os prazos sejam cumpridos, sem que ocorra uma sobrecarga física e psíquica de parte da equipe.

o fato da diretoria de planejamentos e projetos agrupar muitas atividades requer a delegação de poder para alguma arquiteta, subordinado a ela, que possa agir em seu nome e organizar as atividades, sendo uma pessoa mais presente e a par do funcionamento do departamento. A Diretora estará mais disponível para as atividades mais importantes do departamento e não para todas as resoluções, como ocorre hoje.

110 É importante também que se crie uma equipe multidisciplinar que atue internamente à Construtora, para que toda a coordenação dos projetos possa ser realizada com respaldo técnico dos engenheiros. Esse grupo seria responsável pelas melhorias técnicas, avaliação dos métodos construtivos utilizados e pela avaliação dos problemas e criação de soluções, para que não haja dificuldade de entendimento na obra, falta de retorno de informações, nem mesmo a perda do registro das atividades realizadas. 
111 É necessário que se disponibilize alguns serviços da empresa para o departamento, para servir de apoio às tarefas mais simples, como por exemplo, estagiárias, boys e uma secretária, reduzindo assim, parte da carga de trabalho imposta às arquitetas, uma vez que o departamento é visto como fonte de informações para toda a empresa.

112 Outra sugestão é a criação de horários definidos para atendimento, tanto por telefone como para visitas, à obra, a clientes e fornecedores e reuniões semanais com a diretoria e engenharia, para que elas possam reservar horários no dia para atividades que requeiram concentração sem serem perturbadas.

\subsection{0 novo espaço físico - a demanda inicial}

113 A falta de privacidade pode ser solucionada com estudos de layout, criação de salas de reunião e, principalmente, com a tomada de consciência por parte de toda a empresa da importância das atividades realizadas no departamento, levando em conta a necessidade de se promover um ambiente propício para a arte de projetação.

114 O novo layout proposto buscará atender e solucionar às principais queixas das arquitetas. Nenhum posto estará imediatamente de costas para a porta e para a sala da Diretora, tampouco nenhuma das arquitetas ficará imediatamente ao lado da outra, aumentando a privacidade individual de cada trabalhadora. A disposição em ilha escolhida atende a essa necessidade, além de ampliar os espaços, reduzir a quantidade de áreas desperdiçadas, possibilitar economia para a parte elétrica e melhor interação entre as arquitetas e quebra de hierarquias inexistentes. Para se manter a privacidade externa, é necessário que se utilizem persianas, que também servirão para bloquear a luz solar refletida em parte dos postos de trabalho. O departamento poderá ser ampliado juntamente com a construção da nova sede da empresa. A previsão é que a obra seja finalizada no final de 2010. Será construída uma sala de reuniões e área para armazenamento de materiais e catálogos, liberando a região atualmente com esse fim somente para arquivamento de projetos e livros. Essa área atuará como uma ante-sala para o departamento, além de separar o trecho de grande fluxo e reuniões da área que necessita de mais reserva, a dos postos de trabalho. Ela atuará como uma dimensão de transição do espaço público externo da Construtora, para o espaço privado do departamento.

\section{Considerações finais}

Buscamos através do diagnóstico feito e da análise da subjetividade dos sujeitos compreender a atividade das arquitetas, os determinantes físicos, cognitivos ou psíquicos e os impactos negativos ou positivos para a saúde.

116 Os resultados encontrados nos permitem afirmar que as arquitetas estão submetidas a fortes constrangimentos de tempo, formas híbridas de controle, pressão por produtividade, altas cargas de trabalho, auto-aceleração, dificuldades de comunicação e de relacionamento e a conflitos causados pelo distanciamento entre o prescrito e o real. Além disso, não têm suas competências criativas reconhecidas.

117 Nossa investigação leva à conclusão de que, o trabalho das arquitetas gera sofrimento, configurando num trabalho penoso. As condições de trabalho destas arquitetas se configuram nocivas à saúde, pois as margens postas pela organização do trabalho 
constrangem o trabalhador e reduzem suas possibilidades de construção da saúde (Assunção \& Lima, 2003).

118 Apesar de termos comprovado a necessidade de mudança, é importante primeiramente, o envolvimento de todos, uma vez que a demanda foi apenas formulada pelos trabalhadores, sem o apoio e interesse da direção da empresa. Desta maneira, a transformação só poderá ser realizada se diferentes pontos de vista dos atores sociais envolvidos forem confrontados, se o diagnóstico feito for validado e se ele for divulgado para além dos interlocutores imediatamente envolvidos na atividade analisada. Para contribuir em longo prazo com a preservação da saúde dos trabalhadores e a manutenção do equilíbrio saúde versus trabalho, torna-se imperativo que os resultados técnicos e sociais desta pesquisa sejam incorporados por todos os atores sociais, não somente pelo grupo de arquitetas, e adquiram uma legitimidade que resista ao tempo. Para tal, é necessário que o ponto de vista da atividade permaneça dentro da política da construtora e passe a conduzir o processo de decisão técnico-organizacional com a participação de quem executa o trabalho. Somente assim, evita-se que as modificações a serem realizadas sejam inapropriadas, nocivas à saúde dos trabalhadores e/ ou apropriadas pela organização do trabalho (Cockell, 2004).

Uma das primeiras conquistas do grupo foi à efetivação da arquiteta mais antiga no setor, como Gerente de Projetos. No entanto, conforme nos relataram, apesar de num primeiro momento, a criação deste cargo sugerir maior autonomia para arquitetas, o que vêm ocorrendo na prática é a continuidade do poder de decisão exclusivo da Diretora do setor. Desta maneira, mesmo após a criação do cargo de Gerente, os projetos continuam atrasando à espera das decisões unilaterais da diretoria.

É evidente que no caso apresentado, os espaços sociais de negociação são poucos e limitados. As arquitetas encontram dificuldades para implementar quaisquer modificações que necessitem apoio financeiro e mudanças organizacionais efetivas. Acreditamos que o estudo realizado poderá contribuir com a produção e transferência dos conhecimentos sobre os condicionantes impostos pela separação radical entre a concepção das condições e organização do trabalho e a execução da atividade pelo grupo de arquitetas estudadas. Sabemos que o não envolvimento efetivo da diretoria impede que uma série de mudanças necessárias sejam implementadas. Entretanto, podemos inferir, a partir das primeiras modificações, que a incorporação do ponto de vista da atividade pelas arquitetas, poderá alterar a atual interação social destas com os planejadores do trabalho a elas prescrito, transformando, mesmo que paulatinamente, a nocividade das condições de trabalho ao imputar ao grupo maior poder de percepção dos problemas enfrentados e maior capacidade de reivindicação social através da formação de um coletivo, inexistente no modelo atual de avaliação individual.

Acreditamos que por se tratar de uma atividade complexa e de grande responsabilidade e por o arquiteto influir na base da produção da construtora é fundamental que seu trabalho seja mais valorizado e que o processo de projeto seja adequado às exigências reais da atividade do arquiteto. Há a necessidade de novos estudos sobre a atividade dos arquitetos, capazes de contribuírem com a nossa reflexão a respeito das conseqüências da informatização na extração do "saber-fazer" destes profissionais, sobre as "novas" estruturas temporais do trabalho do arquiteto e sobre a individualização progressiva da profissão. 


\section{BIBLIOGRAFIA}

Abrahão, J. \& Pinho, D. (2002). As transformações do trabalho e desafios teóricos e metodológicos da ergonomia. Estudos de Psicologia, 7, 1-24.

Almeida, M. (2002). Ergonomia e arquitetura : uma vinculação transdisciplinar. Anais do $12^{\circ}$ Congresso Brasileiro de Ergonomia, Brasil, 1-4.

Assunção, A. \& Lima, F. (2003). A contribuição da ergonomia para a identificação, redução e eliminação da nocividade do trabalho. In R. Mendes (Org.), Patologia do trabalho (pp. 1767-1789). São Paulo : Atheneu.

Bassalo, J. (1995). o Computador sobre a Prancheta. Reflexões sobre a utilização da Informática na Concepção dos Espaços Arquitetônicos. Retirado em Abril, 26, 2008, de http://www.amazon.com.br/ jbassalo/artigos.htm.

Brandimiller, P.A (1997). O corpo no trabalho. Guia de conforto e saúde para quem trabalha em microcomputadores. São Paulo : Senac.

Brasil, Ministério do Trabalho e Emprego (2002). Manual de aplicação da Norma Regulamentadora $n^{\circ}$ 17 (2ed.). Brasília : SIT.

Campello, J., Oliveira, P., Netz. J. \& Machado, M. (2002). Aplicação de uma metodologia de intervenção ergonômica a partir da demanda e organização dos trabalhadores : a experiência do sindicato dos bancários de porto alegre. Anais do $12^{\circ}$ Congresso Brasileiro de Ergonomia, Brasil, 5-9.

Cockell, F. (2004). Incorporação e apropriação dos resultados de uma intervenção ergonômica : um estudo de caso. Dissertação de Mestrado. Universidade Federal de São Carlos, São Carlos-SP.

Dejours, C. (1998). A banalização da injustiça social. Rio de Janeiro : FGV.

Dejours, C. (2008a). Cadernos de TTO, 2 - A avaliação do Trabalho Submetida à prova do real. São Paulo : Blucher.

Dejours, C. (2008b). A metodologia em psicopatologia do trabalho. In S. Lancman \& L. Sznelwar (Orgs.), Christophe Dejours : da psicopatologia à psicodinâmica do trabalho (pp. 107-128). Rio de Janeiro : Fiocruz.

Farah, M. (1996). Processo de Trabalho na Construção Habitacional : Tradição e Mudança. São Paulo : Annablume.

Foucault, M. (1994). Vigiar e Punir : nascimento da prisão. Petropolis : Vozes.

Guérin, F., Laville, A., Daniellou, F., Durrafourg, J. \& Kerguellen, A. (2001). Compreendendo o trabalho para transformá-lo - A Prática da Ergonomia. São Paulo : Edgard Blucher LTDA.

Habermas, J. (1975). Técnica e ciência enquanto 'ideologia'. São Paulo : Abril Cultural.

Leite, M. (2003). Trabalho e Sociedade em transformação : mudanças produtivas e atores sociais. São Paulo : Fundação Perseu Abramo.

Malaguti, M. (1996). A ideologia do modelo japonês de gestão. Ensaios FE, 17,1, 43-73.

Merlo, A. (1997). Tecnologia da informação e doenças do trabalho : um estudo sobre o processamento de massa de dados no Brasil. Saude Revista do Nipesc, 2, 41-52.

Rêgo, R. (2001). As naturezas cognitiva e criativa da projetação em arquitetura : reflexões sobre o papel mediador das tecnologias. Revista da. Escola de Minas, 54, 1, 33-40. 
Ruth, W. (2000). Desenvolvimento tecnológico e processos de mudança na via do trabalho : Uma abordagem através dos atores. In L. Sznelwar \& L. Zidan (Orgs.), O trabalho Humano em sistemas informatizados no setor de serviços (pp. 322-351). São Paulo : Plêiade.

Santos, N. \& Fialho, F. (1995). Manual de análise ergonômica do trabalho. Curitiba : Ed. Gênesis.

Sato, L. (1993). A representação social do trabalho penoso. In M. Spink (Org.), O conhecimento no cotidiano : as representações sociais na perspectiva da psicologia social (pp. 188-211). São Paulo : Brasileiense.

Silva, E. (1994). Uma história de "crise de nervos" : saúde mental e trabalho. In J. Buschinelli, L. Rocha \& R. Rigotto (Orgs.), Isto é Trabalho de Gente ? Vida, doença e trabalho no Brasil (pp. 609-635). Petrópolis : Vozes.

Speck, H. (2005). Proposta de método para facilitar a mudança das técnicas de projetos : da prancheta à modelagem sólida (CAD) para empresas de engenharia de pequeno e médio porte. Tese de Doutorado, Universidade Federal de Santa Catarina, Florianópolis.

Thompson, E. (1998). Tempo, disciplina do trabalho e o capitalismo industrial. In Costumes em comum (pp. 267-304). São Paulo : Companhia das letras.

Wisner, A. (1994). A inteligência no trabalho : textos selecionados de ergonomia. São Paulo : Fundacentro.

Wisner, A. (2004). Questões epistemológicas em ergonomia e em análise do trabalho. In F. Daniellou (Org.), A ergonomia em busca de seus princípios : debates epistemológicos (pp. 29-55). São Paulo : Edgard Blücher.

Zarifian, P. (2002). Engajamento subjetivo, disciplina e controle. Novos Estudos CEBRAP, 64, 23-31.

\section{RESUMOS}

Este artigo tem como objetivo analisar a atividade de trabalho de um grupo de arquitetas de uma empresa de construção civil brasileira. A partir da demanda elaborada pelas trabalhadoras, buscamos analisar como elas percebem os conflitos vivenciados no cotidiano de trabalho e como este se apresenta nocivo à saúde. Verificamos que elas são submetidas a fortes pressões de tempo e produtividade, a altas cargas de trabalho e a conflitos causados pelo distanciamento entre o prescrito pela construtora e a atividade de concepção dos projetos arquitetônicos. Torna-se evidente como a falta de reconhecimento de suas competências criativas e como as dificuldades de comunicação com os demais atores sociais têm causado sofrimento físico e psíquico para o grupo. Apesar do não envolvimento da diretoria da construtora, os resultados encontrados podem ser um instrumento de reivindicação social capaz de transformar, mesmo que paulatinamente, a realidade de trabalho.

Este artículo tiene como objetivo analizar la actividad de trabajo de un grupo de arquitectos de una empresa de construcción en Brasil. De la demanda producida por los trabajadoras, tratamos de examinar cómo perciben los conflictos experimentados en el trabajo diario y cómo este se presenta perjudicial para la salud. Encontramos que son sometidas a fuertes presiones de tiempo y de productividad, a gran carga de trabajo y a conflictos causados por la distancia entre los requisitos para la actividad de la construcción y el desarrollo de los proyectos. Se hace evidente que la falta de reconocimiento de sus capacidades creativas y las dificultades de comunicación con otros actores sociales han causado dolor y sufrimiento para el grupo. A pesar de la falta de participación de la gestión de empresa, los resultados pueden ser un instrumento de lucha social, que puede transformarse, aunque lentamente, la realidad del trabajo. 
Cet article reprend l'analyse de l'activité de travail d'un groupe d'architectes d'une entreprise du bâtiment au Brésil. A partir de la demande émise par des travailleuses, on a analysé la façon dont elles perçoivent les conflits survenus dans le cours du travail quotidien et comment celui-ci s'est avéré nuisible à leur santé. Nous avons mis en évidence : les fortes pressions exercées sur les architectes en termes de délais et de productivité ; les charges de travail élevées; et les conflits provoqués par l'écart entre les exigences de l'entreprise et ce qu'exige le développement des projets. Il est devenu évident que le manque de reconnaissance de leurs compétences créatives ainsi que les difficultés de communication avec d'autres acteurs sociaux ont été à la source d'une souffrance physique et psychique pour le groupe. En dépit de la non-participation de la direction de l'entreprise, les résultats obtenus peuvent constituer un instrument de revendication sociale, et contribuer à transformer, lentement, la réalité du travail.

This article aims to analyze the work activity of a group of architects of a construction company in Brazil. From the demand produced by the workers, we investigated how they perceive the conflicts experienced in the daily work and how it presents itself harmful to health. We found that they are under enormous pressures of time and productivity, high workloads and conflicts caused by the difference between the requirements for construction activity and development of the projects. It becomes evident as the lack of recognition of their creative skills and the difficulties of communication with other social actors have caused physical and physical suffering for the group. Despite the non-involvement of company director, the results can be an instrument of social claim, it can transform, even if slowly, the reality of work.

\section{ÍNDICE}

Mots-clés: travail, activité de l'architecte, souffrance, nocivité

Palabras claves: trabajo, actividad del arquitecto, sufrimiento, perjudiciales

Keywords: work, activity of the architect, suffering, hazard

Palavras-chave: trabalho, atividade do arquiteto, sofrimento, nocividade

\section{AUTORES}

\section{FERNANDA FLÁVIA COCKELL}

Universidade Federal de São Carlos, São Carlos-São Paulo, Brasil

fercockell@yahoo.com.br

DANIEL PERTICARRARI

Universidade Federal de São Carlos, São Carlos-São Paulo, Brasil dperticarrari@yahoo.com.br

\section{ALESSANDRA MARA COCKELL}

Universidade Federal de Minas Gerais, Belo Horizonte-Minas Gerais, Brasil

alecockell@hotmail.com 